\title{
ASSESSMENT OF SOCIO-DEMOGRAPHIC FACTORS AND HEALTH STATUS OF POST- MENOPAUSAL WOMEN IN JAMSHORO, SINDH
}

\author{
Syed Qararo Shah ${ }^{1}$, Allah Bux Ganghro², Abdul Rasool Abbasi ${ }^{3}$, Bharat Kumar Maheshwari ${ }^{4}$, Imdad Ali \\ Khushk $^{5}$
}

${ }^{1}$ Deputy Director (NRIFC) National Research Institute of Fertility Care Karachi. Ministry of National Health Services Regulations and Coordination Pakistan.

${ }^{2}$ Institute of Biochemistry University of Sindh Jamshoro, Sindh, Pakistan

${ }^{3}$ Institute of Fresh Water Biology University of Sindh Jamshoro, Sindh, Pakistan.

${ }^{4}$ Medical Officer (NRIFC) National Research Institute of Fertility Care Karachi. Ministry of National Health Services Regulations and Coordination Pakistan.

${ }^{5}$ Pakistan Medical and Dental Council

Islamabad

Correspondence: Syed Qarar Shah, Cell:03363138358, Email: shahsb29@yahoo.com

\begin{abstract}
Background: Menopause is a very crucial phase of a woman's life making her vulnerable to various medical and psychological problems. If not understood and taken well care of, it may lead to decreased quality of life and morbidities.

Methods: This descriptive study was conducted in district Jamshoro Sindh-Pakistan with a sample of 264 postmenopausal women of age ?40 years. Pre-mature menopause cases were excluded. The data was collected through specifically designed questionnaire through house to house visits and analysis was done by using SPSS version 21.0. The ethical approval of the study was granted by Research and Evaluation Committee of Sindh University, Jamshoro.

Results: The age of postmenopausal women ranged from 40 to 90 years with mean of $56.69 \pm 12.587$ years. The majority of postmenopausal women belonged to 50-59 years group ( $n=92,35 \%)$. Three-fourth of women reported no formal education as well as monthly household income of PKR 5,000-10,000. Majority of women $(n=198,75 \%)$ were married. The most common medical problems among these women were Hypertension $(n=97,37 \%)$, liver disease $(n=87,33 \%)$, Diabetes Mellitus $(n=25,9.5 \%)$ Kidney disease $(n=25,9.5 \%)$, Sleep disturbance $n=14,5.3 \%$, severe forgetfulness ( $n=14,5.3 \%$, Anxiety \& Depression $(n=11,4.2 \%)$, Heartburn ( $n=11,4.2 \%)$ etc. Hypercholesterolemia, Heart disease, Stroke, Joint/ muscular discomfort and Urine incontinence were very uncommon among these women. However, nutritional supplements intake increased with increasing level of monthly income.

Conclusion: This study has found that post -menopausal women in district Jamshoro have poor sociodemographic indicators and common health problems in these women include hypertension, liver diseases and kidney diseases etc.
\end{abstract}

Keywords: Menopause. post-menopausal period. Symptoms, health, socio-demographic characteristics.

\section{Introduction}

Permanent cessation of menstruation is a very critical phase of a woman called as menopause appearing at age between 40-60 years (Median age 51 years) $(1,2)$. This universal phenomenon of transition from fertility to infertility brings about many physiological changes in her body due to declining estrogens and elevating gonadotropins hormones levels (3). Post-menopausal stage is when menstrual cycle stops not less than 12 months with decrease in estrogen and progesterone hormones in the body. Though; menopause is a natural process but due to inconsistency in hormone levels, it gives rise to unnatural and abnormal states of health of women $(4,5)$. These changes may range from somatic and sexual to vasomotor and physiological signs/ symptoms and can play role as precursors/ risk factors of variety of acute and chronic medical conditions like osteoporosis and fractures, coronary heart disease, stroke, cancers, eye disorders, such as glaucoma, gastrointestinal or urinary tract problems including frequent constipation, cystitis and urethritis $(6,7)$.

Investigation of the health status of postmenopausal women is mandatory because these women lack autonomy and access to health facilities in our society. Studies have shown that the nutritional, genetic, sociocultural, occupational and behavioral factors are 
related with menopause and postmenopausal life of a woman in one way or other $(5,8-10)$. Therefore; assessment of psychosomatic, neurological, physiological, systemic and social as well as sexual dysfunction problems experience by women should be brought to our knowledge.

This study will help detection of and also measure the magnitude of burden of most common of their health related problems and understand the mechanisms by which menopause cause such an important impact on the occurrence of chronic diseases. This way specific intervention focusing their needs may be developed and introduced. Thus; it will help reduce the burden of acute disease and treat preemptively chronic disease and taking appropriate medical measures \& advising dietary \& lifestyle modification to this largely ignored population of our society. This study was conducted with the objective of assessment of Socio-demographic status and prevalence of different disease conditions among postmenopausal women Jamshoro district.

There was very limited and old data available at local level in this regard and that available was even only patients sampled from clinical set-up. Contrary to this, the present study focused the community where majority of these women live and rarely present to clinical set-up.

\section{Methodology}

This descriptive study was conducted during March to June 2016. The study area selected was Lady Health Workers (LHWs) covered, industrial area of district Jamshoro Sindh-Pakistan while the study population was postmenopausal women. A sample of 264 postmenopausal women aged $>40$ with definite diagnosis of menopause were included after obtaining the informed and written consent. Menopause was defined as permanent cessation of menstrual period for more than 12 months. Women below 40 years despite of menopause (pre-mature menopause) were excluded. Ethical approval of the study was granted by the Research Evaluation Committee of Sindh University, Jamshoro. The data were collected through a specifically designed pre-tested questionnaire during house to house visits. Data were taken on sociodemographic variables and medical conditions which prevailed among the postmenopausal women. Data were analyzed through SPSS version 21.0. Results are expressed as mean \pm standard deviation for quantitative and percentages for qualitative variables. Stratified analysis was run applying chi-square test with $p$ value $<0.05$ taken as significant.

\section{Results}

This study was conducted to assess the sociodemographic data and their relationship with the prevalent medical disorders among postmenopausal women. All 264 participants responded to the questionnaire. All women belonged to rural area of Jamshoro district. The age of the postmenopausal women ranged from 40 to 90 years; with mean age \pm SD $55.69 \pm 12.587$. Majority of these women belonged to 50-
59 years group ( $n=92,35 \%)$. The socio-demographic indicators of the study sample are presented in Table I.

Table I: Socio?demographic characteristics of post-menopausal women

\begin{tabular}{|l|l|l|}
\hline Variable & Frequency & Percentage \\
\hline Age groups & 33 & 6.4 \\
$40-44$ years & 80 & 34.9 \\
$\mathbf{4 5}-\mathbf{5 4}$ years & 93 & 36.4 \\
$\mathbf{5 5}-\mathbf{6 4}$ years & 58 & 22.3 \\
$\mathbf{6 5}$ and above & 233 & \\
\hline Education & 16 & 88.2 \\
No education & 12 & 6.1 \\
Primary & 3 & $4.5 \%$ \\
Secondary/Intermediate & & $1.1 \%$ \\
Graduation and above & 52 & 19.7 \\
\hline Monthly Household Income & 145 & 54.9 \\
Up-to 5,000 & 48 & 18.2 \\
Up-to 10,000 & 19 & 7.2 \\
Up-to 15,000 & & \\
Up-to 20,000 and above & 3 & 1.1 \\
& 260 & 98.5 \\
\hline Occupation & 1 & 0.4 \\
Govt Servant & & \\
Housewife & None & \\
\hline
\end{tabular}

Majority of women had no formal education $(n=198$, $75 \%$ ) and were housewives (98.5\%). Only $7.2 \%$ had monthly income of PKR 20,000. Three-fourth of women $(n=198,75 \%)$ were married (Figure I). The common prevalent medical problems in postmenopausal women included Hypertension

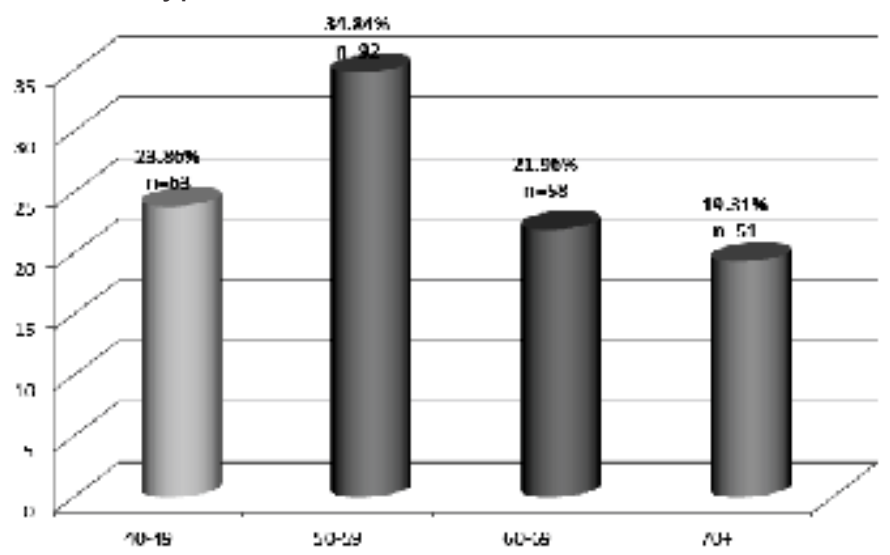

Figure I: Age distribution of post-menopausal women

$(n=97,37 \%$, some of them having very severe level of hypertension despite of history of taking antihypertensive medicine. Liver disease $(n=87,33 \%$,) Diabetes Mellitus $(n=25,9.5 \%$, ) Kidney disease 9.5\%, sleep disturbance $5.3 \%$, sever forgetfulness $5.3 \%$, Anxiety \& Depression $4.2 \%$, Heart burn $4.2 \%$. Hypercholesterolemia, Heart disease, Stroke, Joint/ muscular discomfort and Urine incontinence were very 
uncommon. Family History of Diabetes Mellitus, cancer and Heart disease related deaths were also noted to some proportion (table 2).

Table 2: Frequency of health problems and family history of diseases among post-menopausal women $(\mathrm{N}=264)$

\begin{tabular}{|l|c|c|}
\hline Variable & Frequency & Percentage \\
\hline Hypertension & 97 & $37 \%$ \\
\hline Liver Disease & 87 & $33 \%$ \\
\hline Kidney Disease & 25 & $9.5 \%$ \\
\hline Diabetes Mellitus & 25 & $9.5 \%$ \\
\hline Sleep Disturbance & 14 & $5.3 \%$ \\
\hline Severe forgetfulness & 14 & $5.3 \%$ \\
\hline Anxiety/ Depression & 11 & $4.2 \%$ \\
\hline Heartburn & 11 & $4.2 \%$ \\
\hline Thyroid Disease & 8 & $3 \%$ \\
\hline Joint Pain & 8 & $3.0 \%$ \\
\hline Hypercholesterolemia & 6 & $2.3 \%$ \\
\hline Heart Disease & 5 & $1.9 \%$ \\
\hline Stroke & 3 & $1.1 \%$ \\
\hline Family history of Heart disease related deaths & 26 & $9.8 \%$ \\
\hline Family History of cancer related deaths & 23 & $8.7 \%$ \\
\hline
\end{tabular}

It was found with statistical significance that hypercholesterolemia was more common in women of 40-45 year age than other elder age women $(P=0.055)$. Frequency of Heart disease and Stroke increased with increasing age $(P=0.023 \& 0.116$ respectively $)$. Frequency of Diabetes Mellitus showed a decline $(\mathrm{P}=$ $0.087)$ while kidney disease remained similar thorough age stratifications $(P=0.051)$ with increasing age of postmenopausal women. However, frequency of taking nutritional supplements by postmenopausal women increased with increasing level of month ly income $(P=$ 0.045) (table 3).

Table 3. Stratification by age of postmenopausal women to assess relationship of with different comorbidities

\begin{tabular}{|c|c|c|c|c|c|}
\hline $\begin{array}{c}\text { Age categories/ } \\
\text { Condition }\end{array}$ & $\begin{array}{r}\text { Hyperchol } \\
\text { esterolemia }\end{array}$ & $\begin{array}{c}\text { Heart } \\
\text { Disease }\end{array}$ & Stroke & $\begin{array}{l}\text { Diabetes } \\
\text { mellitus }\end{array}$ & $\begin{array}{l}\text { Kidney } \\
\text { disease }\end{array}$ \\
\hline \multirow{2}{*}{ 40-44 years } & 2 & 17 & 16 & 17 & 16 \\
\hline & $11.8 \%$ & $100.0 \%$ & $94.1 \%$ & $100.0 \%$ & $94.1 \%$ \\
\hline \multirow{2}{*}{$45-54$ years } & 1 & 87 & 92 & 86 & 77 \\
\hline & $1.1 \%$ & $94.6 \%$ & $100.0 \%$ & $93.5 \%$ & $83.7 \%$ \\
\hline \multirow{2}{*}{$55-64$ years } & 2 & 96 & 94 & 87 & 90 \\
\hline & $2.1 \%$ & $100.0 \%$ & $97.9 \%$ & $90.6 \%$ & $93.8 \%$ \\
\hline \multirow{2}{*}{$\begin{array}{l}65 \text { years and } \\
\text { above }\end{array}$} & 1 & 59 & 59 & 49 & 56 \\
\hline & $1.7 \%$ & $100.0 \%$ & $100.0 \%$ & $83.1 \%$ & $94.9 \%$ \\
\hline \multirow{2}{*}{ Total } & 6 & 259 & 261 & 239 & 239 \\
\hline & $2.3 \%$ & $98.1 \%$ & $98.9 \%$ & $90.5 \%$ & $90.5 \%$ \\
\hline Chi-square value & 7.583 & 9.528 & 5.910 & 6.562 & 7.752 \\
\hline Pvalue & $0.055 *$ & $0.023 *$ & 0.116 & $0.087 *$ & $0.051^{*}$ \\
\hline
\end{tabular}

\section{Discussion}

Menopause is an insidious onset but life changing event for a woman when she starts encountering an entire range of physiological changes which have lasting impact on her life then and thereon. Women facing menopause need to be evaluated for the disorders which they come across along with the psychological, medical, emotional and social support. Management of these issues has therefore, evolved into an entirely significant field of medical care and research world over (11). However, women of rural areas especially locally, suffer more compared to the urban living women due to limited accessibility and affordability to these management options $(12,13)$. The current study attempted to investigate these disorders and their relation with some of socio-demographic characteristics in one such population of Jamshoro district.

This study noted that mean age \pm SD of postmenopausal women was $56.99 \pm 10.797$ with a range of $40-90$ years. Other contemporary studies have documented that mean age of postmenopausal women ranges from 40.32 to 48.84 years $(14,15)$ and in developed countries from 48.29 to 57 years (16-19). Two thirds of all women in current study were between age of $45-65$ years. Late age menopause and poor economic status make these women prone to worsening of quality of life which ultimately negatively affects their attitudes (20-22). Negative attitudes include irritability, anger, fatigue, lack of concentration, excessive sweeting, sleep disturbance and forgetfulness which were also found in the current study but a lesser frequency compared to other studies (23-26). Another study found that postmenopausal women are at greater risk of psychological symptoms with higher scores on the depression scale (27).

In current study majority of the post-menopausal women were from poor socioeconomic background and belonged to labor class and were housewives with very low monthly family income. Most of them were having no formal education. Wieder-Huszla S, et al., reported that there was significant relationship of age and educational level of postmenopausal women with the medical conditions like body pain and others. Over all they detected significant relationships between quality of life and socio-demographic characteristics i-e; age, education, employment status, and monthly income (19). Other study by Christian D and coworkers from rural areas of India documented that most of postmenopausal women were illiterate, labor class or housewives and living below poverty line (14). These women were facing multiple medical disorders. Similar were the finding of the current study where in three fourths of women were having very low income, no formal education, were housewives and dealing with medical disorders ranging from diabetes, hypertension, other cardiovascular (Hypercholesterolemia, Heart Disease and Stroke), liver and kidney disease, headache, sleep disturbance and psychiatric disorders like anxiety and depression. It was important to note that 
prevalence of hypertension among postmenopausal women is alarmingly high as seen in this study $36.7 \%$. Assessment of sexual dysfunction is also an important aspect of postmenopausal life but it was beyond the scope of this study. Although coexisted, yet no any causal relationship could be expressed between majority of the disease conditions faced by the women and the postmenopausal status directly.

Nutritional supplementation including calcium and multivitamins are also universally recommended for this age group however; it was significantly noted that women with better financial resources/monthly income had been taking nutritional supplementation even that to a little extent. It is of paramount importance that these retired life living women are in of need special geriatric care focusing their postmenopausal symptoms and any acute/ chronic disease. If not taken care wise, they may suffer many social disadvantages which could make them more vulnerable to experience more frequent and more severe of menopausal symptoms. The current study with limited focus and scope has highlighted a very important group of population living around us however in need of some special treatment regarding their overall health.

\section{Conclusion}

This study has found that post -menopausal women in district Jamshoro in our set - up have poor sociodemographic indicators and common health problems in these women include hypertension, liver diseases and kidney diseases etc. These findings are comparable with national and international literature.

\section{References}

1. North American Menopause Society. Menopause practice:a clinician's guide. 3rd ed. Cleveland, $\mathrm{OH}$ : North American Menopause Society. 2007.

2. Izetbegovic S, Stojkanovic G, Ribic N, Mehmedbasic E. Features of postmenopausal uterine haemorrhage. Med Arch. 2013;67(6):431-4.

3. Nelson LM. Clinical practice. Primary ovarian insufficiency. NEngl J Med. 2009;360:606-14.

4. Farahmand M, Tehrani FR, Pourrajabi L, Najafi M, Azizi F. Factors associated with menopausal age in Iranian women: Tehran Lipid and Glucose Study. J Obstet Gynaecol Res. 2013;39(4):83641.

5. Avraham Y, Nachum S. Management of obesity in menopause: Lifestyle modification, medication, bariatric surgery and personalized treatment. Current Topics in Menopause. Oak Park, II, USA: Bentham Science; 2013:143-162.

6. Butt Z, Haider SF, Arif S, Khan MR, Ashfaq U, Shahbaz U, et al. Breast cancer risk factors:a comparison between premenopausal and postmenopausal women. J Pak Med Assoc. 2012;62(2):120-4.

7. Mamji MF, Hasan JA, Sabri MS. Risk factors for osteoporosis in post-menopausal women with hip fractures. J Surg Pak. 2010;15(2):82-6.

8. Deeks AA, McCabe MP. Well-being and menopause: an investigation of purpose in life, self-acceptance and social role in premenopausal, perimenopausal and postmenopausal women. Qual Life Res 2004;13(2):389-98.

9. World Health Organisation. Research on the menopause 1990s. Report of a WHO scientific group, WHO Technical Report Series 1996;886:1-107.

10. Dasgupta D, Ray S. Menopausal Problems among rural and urban women from eastern India. J Social, Behav Health Sci. 2009:1-24.

11. Upton GV. The perimenopause: physiological correlates and clinical management. J Reprod Med. 1982;27:1-27.

12. Green R, Santoro N. Menopausal symptoms and ethnicity: the Study of

Women's Health Across the Nation. Womens Health 2009;5(2):127-33.

13. Avis NE, Crawford S. Cultural differences in symptoms and attitudes toward

menopause. Menopause Manage 2008;17(3):8-13.

14. Christian D, Kathad M, Bhavsar B. Sociodemographic characteristics of postmenopausal women of rural area of Vadodara district, Gujarat. National J Comm Med. 2011;2(3)41922.

15. Sharda S, Kaur A, Mandeep S. Age at menopause in educated women of Amritsar (Punjab). J Hum Ecol 2005;18(1):49-51.

16. Nitika B, Sharma SS. Onset age of menopause among women in Kangra district of Himachal Pradesh. The Anthropologist.2008;10(4):30507.

17. Kim $\mathrm{YH}, \mathrm{Ha} E \mathrm{EH}$, Shin SJ. A study on the menopausal symptoms and quality of life in middle aged women. Taehan Kanho Hakhoe Chi. 2003;33(5):601-8.

18. Sharma S, Tandon V, Mahajan A. Menopausal symptoms in urban women. JK Science. 2007;9(1):13-17.

19. Wieder-Huszla S, Szkup M, Jurczak A, Samochowiec A, Samochowiec J, Stanis?awska M, et al. Effects of sociodemographic, personality and medical factors on quality of life of postmenopausal women. Int $\mathrm{J}$ Environ Res Public Health. 2014 Jun 26;11(7):6692-708.

20. Shah R, Kalgutkar S, Savardekar L, Chitlang S, Iddya $U$, Balaiah D. Menopausal symptoms in urban Indian women. Menopausal symptoms in urban Indian women. Obs \& Gynae Today. 2004; 11(10):667-70.

21. Bagga A. Age and symptomatology of menopause: a case study. Obs \& Gynae Today. 
2004;11(10):660-6

22. Deeks AA, McCabe MP. Well-being and menopause: an investigation of purpose in life, self-acceptance and social role in premenopausal, perimenopausal and postmenopausal women. Qual Life Res. 2004;13(2):389-98.

23. Hess R, Olshansky E, Ness R, Bryce CL, Dillon SB, Kapoor W, et al. Pregnancy and birth history influence women's experience of menopause. 2008 May-Jun;15(3):435-41.

24. Cheng $\mathrm{MH}$, Wang SJ, Wang $\mathrm{PH}$, Fuh JL. Attitudes toward menopause among middleaged women: a community survey in an island of Taiwan. Maturitas. 2005;52(3-4):348-55.

25. Hess R, Bryce C, Hays R. Attitudes towards menopause: status and race differences and the impact on symptoms. Menopause. 2006;13(6):986.

26. Huffman SB, Myers JE, Tingle LR, Bond LA. Menopause symptoms and attitudes of African American women: closing the knowledge gap and expanding opportunities for counseling. J Counsel Dev. 2005;83(1):48-56.

27. Wilbur J, Miller A, Montgomery A, Haworth Continuing Features Submission. The influence of demographic characteristics, menopausal status, and symptoms on women's attitudes toward menopause. Women \& Health. 1995;23(3)19-39. 